Rabino Prof. Roberto Feldmann

\title{
Mesianismo y milenarismo desde la perspectiva judía
}

\section{INTRODUCCIÓN}

Mi buen amigo y colega Dr. Antonio Bentué me enseñó que, a su parecer, el judaísmo, entre muchas otras cosas, era una "cultura de la sospecha". Llevaba una tendencia a mirar debajo de lo aparente. Y le he dado la razón, primeramente porque también lo detecto en mí mismo, aunque -gracias a Dios- no obsesivamente... -aún-. Esa sospecha está en Freud, por ejemplo. Y esa tendencia lo llevó a aportes fundantes de nuestra comprensión de nosotros mismos hoy en día.

No puedo resistir la tentación de preguntarme entonces: Más allá de Lacunza -de bendita memoria-, ¿qué motivará en nuestra alma, nuestra psique, que nos reunamos a reflexionar ahora sobre umbrales, cambios epocales y sus expresiones religiosas históricas: Apocalipsis, mesías, escatología? ¿A qué deseos o temores aludirá? Y tratando cautelosamente de responder a esa pregunta, voy a iniciar mi exposición con una mirada universalista al temor y la esperanza que habita en la intuición que anticipa el cruce de un umbral de conciencia epocal. Me propongo contemplar conceptos y ejemplos en torno a las psicologías de umbral, tanto colectivas como individuales, que nos lleven a distinguir entre las imágenes arquetípicas que emergen ante umbrales, y las transformaciones verdaderas de las que esas imágenes vienen preñadas. Estas transformaciones las notamos siempre a posteriori.

Con ese telón de fondo me sumergiré entonces en el milenarismo y el mesianismo desde una perspectiva judía, en una panorámica religiosa, histórica y literaria, citando textos que me parecen sorprendentes, tanto por lo esperanzadores como por lo desgarradores. Mi panorámica cubrirá desde los tiempos del rey David hasta nuestros días, intentando develar el sentido y las mutaciones del concepto mesiánico judío, centrándome especialmente en la época en que el pueblo judío vivía bajo la opresión romana.

Presento tanto visiones clásicas como revisiones modernas de lo escatológico y mesiánico, lo apocalíptico y utópico en el judaísmo, pasando por la Pascua Judía חOפ (Pésaj) y su sentido de redención, el jasidismo y su carismática vida articulada devotamente en la esperanza mesiánica, y la necesaria reflexión sobria que tras la Shoáh, el genocidio nazi, ha devenido en un estallido de ideas diversas que intentan ajustarse espiritual y religiosamente al hilo conductor de este misterio de supervivencia y vida, amor y lealtad, que es la historia del pueblo judío. 


\section{EL TEMOR Y LA ESPERANZA MILENARISTA}

En las diversas corrientes y contracorrientes del universo budista, encontramos en común la idea que miedo y esperanza son dos caras de una misma moneda. Ambas caras son anticipos, más allá de su tonalidad positiva o negativa. Constituyen una huida del presente.

Hay mucho de cierto en ello. No obstante, la tradición judía ve en el apego a Dios -aunque neurótico también- un valor maravillosamente hondo y transformador, no un espejismo. Y valora tanto el amor y el temor reverencial a Dios como la esperanza mesiánica. En el apego, nos parece que hay mucho que crecer y refinarnos. En el jasidismo, el término devocional clásico es דבקות (dvekut) que es literalmente "apego" a Dios. Budismo y judaísmo aparecen, en este aspecto, opuestos en su actitud hacia la vida.

Ambas culturas, sin embargo, junto a la cultura cristiana, la islámica, y todas las otras manifestaciones de lo sagrado, sean de pueblos originarios, de Occidente y Oriente, de Norte y Sur, estamos permeadas hoy por una sensación de umbral. Más allá de lo que sospechemos sea cultural, artificial o comunicacional, existen peligros reales y tremendos. Hay peligros globales que hacen obsoleto el aislamiento en mesianismos particulares: peligros tan substanciales que amenazan la vida toda sobre el planeta. Y la amenazan tanto para el que navega con internet como para quien camina kilómetros por un pozo de agua apenas potable.

Quien sabe qué es huevo y qué es gallina: si el cambio de folio numérico genera la ansiedad milenarista, o al revés. Probablemente sean una sincronía.

Lo que sí se puede afirmar, es que cambios y trastornos profundos ocurren en una sociedad antes y durante un paso de umbral. (Prefiero "paso de umbral", y no "de milenio", para ampliar el concepto más allá de la numeración gregoriana de los años, que, obviamente, no es aplicable al judaísmo. Aunque nos afecta por innegable osmosis cultural también, así como virtualmente a la humanidad entera, hoy por hoy.)

\section{PSICOLOGÍAS DE LA MANIFESTACIÓN MILENARISTA}

Las psicologías de umbral -como me permito llamarlas aquí- permean el milenarismo de toda índole: milenarismo devenido en pensamiento utópico, apocalíptico o mesiánico. Su expresión particular depende de la inclinación particular de cada individuo. En cada cual toma formas distintas. Lejos de mí la ironía y más lejos aún la aplanadora. Solo planteo que ante umbrales, las reacciones psicológicas, pueden tomar expresiones muy diferentes. Sea la noción de un inminente encuentro con seres de otros mundos, sea la noción del inminente regreso de Cristo, o de la inminente llegada del mesías hijo de David. Todo ello, según cada cual, tanto como fantasías apocalípticas de contenido futurista, nuevo-testamental o antiguo-testamental. O desbordes de hedonismo que también llevan el sello del "antes que sea tarde". Reitero que no equiparo moral ni valóricamente unas con otras.

Digo que algo ocurre en el inconsciente colectivo ante umbrales de conciencia, que va más allá de las reacciones habituales ante lo que comúnmente llamamos reali- 
dad. Es la sensación de advento, de advenimiento de algo, acaso una muerte, acaso un interregnum, pero ciertamente un sentido de umbral que augura un gran cambio. Probablemente una redefinición de eso mismo que nombramos "realidad", como ha ocurrido con cada vez más frecuencia en el último milenio de la humanidad.

Entonces hay dos elementos: las ansiedades ante el umbral por un lado, y el cambio epocal en sí, por otro. Las primeras son arquetípicas y bastante universales: diluvios, grandes terremotos, encuentros con seres de otros mundos, la venida (primera o segunda) del mesías, la Tierra variando el eje de su rotación, u otros fenómenos astronómicos, cometas, epidemias, guerras. Apocalipsis clásico, nuclear o ecológico.

Señales positivas hay también: anunciaciones de nacimientos, interpretaciones de signos. Proliferación de "revelaciones" tanto selectas como de baratija. Es que el anticipo del umbral puede tomar cualquier octava: desde lo más burdo a lo más refinado, desde lo más grotesco hasta lo más sublime. Mal que mal es un reflejo de la humanidad fragmentada en los individuos que la componemos.

Y esta sensación de advenimiento, ese cambio epocal en sí, que ocurre a un nivel colectivo ante un umbral, es espejo de la sensación de advenimiento en cambios vitales en el individuo humano. Antes de esos umbrales de transformación o expansión, lo onírico se activa, y el ser se preña de su porvenir en latencia. Y el individuo atravesado por el advenimiento colectivo de un milenarismo, genera su propio tropismo ante él, de acuerdo con su psique o su destino, como sea queramos verlo.

Donde entra en escena el milenarismo es en el hecho de que lo externo lo podemos aspirar a manejar, pero al inconsciente colectivo no. A este lo reconocemos solo cuando ya ha estallado, y hace tiempo, postfacto.

Hay seres humanos, también de todo el abanico de rigurosidad y refinamiento, que tienen conexión con estas corrientes -digamos- subterráneas. Artistas y visionarios en el noble sentido de la palabra. Los límites entre ellos y lo que concebimos como psicótico son difuminados en el mejor de los casos. Otros seres humanos aprenden a manipular estas corrientes para bien o para mal, desde la política, la religión, la comunicación.

Al individuo se le puede hacer terapia. Al colectivo no. Al menos no de un modo sistemático. Solo hay -y muy de vez en cuando- espacios catárticos.

Podemos trabajar en nuestra receptividad personal a estas fuerzas relativas a umbrales, pero no a las fuerzas en sí. La naturaleza de estas fuerzas es muy poderosa, creativa, y no tiene por qué expresarse de un modo destructivo solamente. De hecho, su destructividad, según Freud, es directamente proporcional al nivel de represión con que las confrontamos. Si las acompañamos de un modo sereno y consciente, potenciamos nuestra apertura de conciencia y ahondamiento en la comprensión de nuestro ser.

Algunos presienten -como dijimos- estos umbrales antes de que se manifiesten. Y sabemos también que estos temores y esperanzas de cambio de folio son cíclicos. Y, sobre todo, sabemos que "el fin del mundo" -como símbolo de cambio de conciencia colectiva- puede ocurrir en términos mucho más sutiles que los obvios.

Un fascinante ejemplo de ello -y uno que atañe hondamente al mundo cristiano- es el siguiente: en el año 1524, Anno Domine, ocurrió un fenómeno astral largamente esperado, con las dos caras de la moneda antes mencionadas, de temor y 
esperanza. Los astrónomos, que eran asimismo astrólogos, anticiparon una conjunción de los siete planetas conocidos en la antigüedad en el signo zodiacal de Piscis. Los siete planetas, que son los "ojos de Dios que circundan la Tierra" -como viera el Profeta (Zacarías 4: 10)-, son Sol, Luna, Mercurio, Venus, Marte, Júpiter y Saturno. No sabían los sabios en ese entonces que Neptuno también transitaba el signo del de Piscis: El signo del pez, el Ictus, la contraseña proverbial de la cristiandad. Lo menos que los astrólogos pronosticaban eran inmensos diluvios, epidemias de locura, o la venida del Salvador luego de una apertura de todas las puertas del infierno. Un astrólogo inglés incluso construyó literalmente un arca, igual que Noé. La persona del siglo XVI no podía pensar en términos de un cambio epocal que parta desde lo interno. No se hablaba de arquetipos, ni de inconsciente colectivo, como lo haría Jung, siglos más tarde.

Y el año 1524 vino, y el año 1524 se fue. Hubo algunas guerras, cosa que jamás dejó de haber, hubo un poco de peste en Provenza, pero nada comparable a la peste del siglo XIV. Aparentemente, los astrónomos/astrólogos se equivocaron medio a medio. Nada aparente ocurrió.

Sin embargo, en 1524, Lutero, el teólogo reformador, y Erasmo el humanista, rompen definitivamente el uno con el otro. La religión y el humanismo científico se escinden el uno del otro. Ese mismo año, Zwinglio realiza la abolición de la misa católica en Zurich. Sabemos lo que siguió: la fractura tremenda de la cristiandad, o dicho de otra manera, de la "verdad" indiscutible de la Iglesia de Cristo. Una fractura tan tremenda que llevó consigo a otros cismas, a reformadores que plantearon doctrinas que hasta el día de hoy diferencian al mundo anglosajón del mundo levantino y mediteráneo, y, por consiguiente, del mundo entero. Y quién podría decir que la herencia de Calvino, y su doctrina escatológica, no está entrelazada con la cultura norteamericana, y que ella tiene un rol en la que tragedia sufrida con el ataque terrorista espantoso el año 2001 en Nueva York. Además, entre Lutero y Erasmo, casi imperceptiblemente y a nivel personal aún, se abre la enorme brecha entre humanismo y religión que sigue penando en Occidente.

Dos personajes apartan radicalmente sus caminos. Solo hoy sabemos parte de la inmensidad de las consecuencias de ello, que siguen vivas y moviéndose. Un movimiento telúrico que llevaría al movimiento intenso del barroco y sus trágicas guerras entre cristianos.

Nada puede emerger a la conciencia sin una forma. Y esa forma tiene que ser una forma posible de ser llevada a cabo por una generación en su estadio de conciencia. 1524 inauguró imperceptiblemente casi, una nueva era que recién mucho más tarde podemos comprender. Pero de que fue, fue.

Y hoy, en este cambio de folio epocal, ante este umbral delante de nuestras narices, en nuestra selva dispersa e interconectada a la vez, ya sabemos que los signos no son los que necesariamente esperamos. Pero sabemos, como diría Jung, que "si algo anda mal en la sociedad, algo anda mal en el individuo. Y si algo anda mal en el individuo, algo anda mal conmigo".

Y por eso que quejarnos del egocentrismo que asumen ciertas búsquedas espirituales hoy en día, puede ser legítimo. Pero a veces somos ciegos al hecho de que ese egocentrismo es una adolescencia, un preludio necesario -aunque ingrato-, a una toma de responsabilidad madura y autónoma de la espiritualidad religiosa de 
cada cual. Se acabó el tiempo de proyectar todo en el prójimo. Se acabó el tiempo de confundir imágenes de cambio, con cambio de verdad; circuncisión del corazón, con conversión verdadera y profunda. Y, sobre todo, es muy probable que el mesías no sea un individuo, sino una opción paulatina pero decisiva en el individuo, una opción de cada uno, cada una de nosotros.

Hecha esta reflexión sobre los temores y esperanzas de un milenarismo (entendido como umbral); y hecha esta reflexión sobre la psicología profunda ante el umbral por un lado, y la manifestación externa de ese cambio de era, por otro, es que podemos adentrarnos a la historia mesiánica judía, comprendiéndola mejor.

\section{LA HISTORIA DEL CONCEPTO DE MESÍAS EN LA TRADICIÓN JUDÍA}

\section{a. En el Segundo Templo}

El concepto de mesías es en verdad un concepto estrictamente postbíblico. Cuando los profetas Ageo y Zacarías esperaron que el reino de David se restaurara con un individuo específico, lo pensaron como un aspecto, una parte, del nuevo tiempo, no como agente de su establecimiento ni menos como autor del mismo.

La Biblia hebrea nos presenta a lo más una prehistoria de mesianismo. En ella podemos distinguir tres etapas:

En la primera, en la cúspide del poder del rey David, aparece la doctrina de que Dios elige a David y sus descendientes a regir sobre Israel hasta el fin de los tiempos. (II Samuel 7; 23:1 - 3, 5). David es el rey ungido. Ungido es משטח (Mashaj) en hebreo, de donde viene la palabra משיח (Mashíaj), mesías en castellano, משיחא (Meshija) en arameo. Ungir con óleo sobre la cabeza, es consagrar a Dios en la antigua cultura de Israel.

Deutero-Isaías habla del rey persa Ciro como el משיח (Mashaj) de Dios, el "ungido de Dios" en el sentido de que también lo es un rey no israelita, escogido para un gran destino y una gran misión (Isaías 45:1).

En la segunda etapa aparece la esperanza de la restauración de la casa real de David, como en el salmo 18, en Amos 9: 11-12; Isaías 11: 10; Oseas 3: 5, Ezequiel 37: 15 en adelante y especialmente de 37: 24 en adelante. Históricamente estamos en la dolorosa fractura del reino de Salomón, entre Jeroboam y Rejoboam.

En la tercera etapa, Isaías transmuta el énfasis desde la perpetuidad de la dinastía hacia las cualidades del futuro rey -recordemos que de carne y hueso-. La fundación de su trono será la justicia, exhibirá celo por justicia, carismáticamente sabrá sentir la diferencia entre lo verdadero y lo falso para ejercer justicia (Isaías 9: 1-6).

Se puede afirmar, sin riesgo, que sin esta etapa que inaugura Isaías, la idea postbíblica de "el mesías" no habría sido posible.

Mesías no existe como designación de una personalidad escatológica en la Biblia hebrea; solo ocurre durante el período del Segundo Templo, después del período Antiguo-Testamental.

Por ello es que hay libros del período del Segundo Templo que, aunque se refieren a una salvación escatológica, no hablan de mesías. Por ejemplo, en el libro de Tobit, en que se habla de la salvación de Jerusalén, y del retorno de los judíos de la Diáspora, un mesías personal está totalmente ausente. 
Lo mismo ocurre con el libro de la sabiduría de Ben Sirá y con el libro de Daniel: allí la figura del "hijo del hombre" es un símbolo de los santos de lo más alto (Capítulo 7). En la asunción de Moisés (Capítulo 10) la figura escatológica es el ángel de Dios, pero un agente de semblanza humana no es mencionado. Y ese es el punto.

En las versiones más antiguas del rezo judío por excelencia hasta nuestros días, la Amidá o Shmonesré, con sus 19 bendiciones, un mesías personal no era mencionado, sino solo el retorno de la Diáspora a Sión y la construcción escatológica de Jerusalén. Incluso en otras antiguas oraciones no aparece la palabra Mashíaj.

En la época del Segundo Templo aparece mayor variedad de figuras mesiánicas que antes. El libro de Zacarías ya menciona a dos figuras mesiánicas: el sumo sacerdote, o כהן צד (Cohen Tzédek), y el rey mesiánico. Ambas figuras, Hierofante y Rey, son importantes para la secta del Mar Muerto. Allí la figura del Sumo Sacerdote prevalece por sobre el rey davídico. La tercera figura que aparece en los rollos del Mar Muerto es "El Profeta de los últimos Días". Tres figuras mesiánicas para las tres funciones del ideal reino judío, en el que existe sacerdocio, profecía y rey.

(I Macabeos 14: 41).

Tenemos conocimiento de los Ebonitas, una secta judeocristiana que afirma que Jesús habría reunido en sí a las tres funciones.

La toma de preponderancia después, del mesías hijo de David, causó la desaparición de las otras herencias escatológicas. Probablemente porque el rey, el reino, el componente más visible y palpable, era lo más urgente y concreto del principio de restauración y autonomía en el imaginario del pueblo judío de la época.

La mención más antigua de un rey escatológico aparece en los Oráculos Sibilinos del 140 a. C. y en la "Visión de los Setenta Pastores" en el Libro de Enosh, unos diez años antes un mesías davídico en la literatura apócrifa se hace común desde el tiempo en que el Macabeo Aristóbolo I aceptó el título de rey. De allí que, como reacción, el mesías davídico adquirió importancia central, como puede verse en los Salmos de Salomón, del 63 a. C. (especialmente el salmo 17).

Finalmente el componente político viene con los enormes sufrimientos de la opresión romana al pueblo judío. Así se cristalizó que en libros posteriores, el mesías davídico es la única figura que aparece. Y aparece así -por citar un ejemplo- en el Apocalipsis Sirio de בררוך (Baruj). No se debe subestimar el peso que tiene el anhelo inmenso de redención nacional y autonomía que se fragua en el sufrimiento bajo el yugo romano. Y ese anhelo es de redención muy tangible y clara, visible para el judío común y corriente. Es con esta figura y este carácter del anhelo redentor en el imaginario del pueblo judío como telón de fondo, que Jesús es conocido por la quinta parte del pueblo judío, aquella que en ese tiempo aún vivía en Galilea y Judea.

Y en tiempos de Jesús, habían surgido algunas traducciones de palabras de la Biblia hebrea al griego que constituían interpretaciones mesiánicas, como en Números 24:17, "El versículo trata del mago Bil’am diciendo: “¡Lo estoy viendo, más no es de ahora; lo estoy mirando, más no es en tiempos cercanos: de Jacob ha salido una estrella y de Israel se ha levantado un cetro, que hiere los costados de Moav, y destruye a todos los hijos del tumulto!". Se hallan traducciones en las que "cetro" es injustificada y arbitrariamente traducido como "hombre", generando la versión me- 
sianista: “...De Israel se ha levantado un hombre”, que ni gramatical ni contextualmente se justifica.

Al sabio judío Filón de Alejandría, en esos tiempos, no le gustaba explicitar las esperanzas escatológicas. Las tareas, atributos y virtudes del mesías dependían de la visión teológica y espiritual de las varias corrientes y sectas judías de la época. Pero una cosa es segura: el o los mesías eran indudablemente seres humanos, caudillos, aun cuando a veces se les atribuyeran cualidades sobrenaturales. Las cualidades políticas no siempre eliminaban a las sobrenaturales.

Sin embargo, el mesías fue siempre un agente de Dios y no un salvador en el sentido cristiano. El pretendiente debía probar su autenticidad por sus hechos, ya que en la época del Segundo Templo, ya no era pesquisable si alguien era descendiente de David o no. Y ese énfasis en los hechos, o digamos signos, también juega un rol en la comprensión o incomprensión que -suponemos- el pueblo judío ofrendó a Jesús. Se esperaban esos hechos, signos, y Jesús llevaba el mensaje tan hermoso como sublime, tan revolucionario como simple, de que él era el signo en sí. De allí su silencio, su renuncia a realizar cualquier signo que lo salvara de su cruel y vertiginosa muerte.

\section{b. En el pensamiento rabínico}

Es muy común que un cristiano conciba al judaísmo como la prolongación directa del Antiguo Testamento. Pero esa imagen de un judaísmo fosilizado en tiempos de sacrificios de animales, y un dios castigador, celoso y guerrero, no puede estar más lejos de la verdad, e ignora tristemente toda la evolución del judaísmo por dos mil años. Sería mucho más cierto afirmar que tal como para los cristianos, Cristo murió y resucitó para los judíos, el judaísmo Antiguo-Testamental murió, y en su lugar nació el judaísmo rabínico, que es el que vivimos hasta estos días. El judaísmo rabínico, transmuta el templo al hogar, el culto sacrificial en el estudio y la oración y el cumplimiento de los preceptos, enriquecidos por la ampliación de la Torá oral; y desde Isaías ya, transmuta el dios local, tribal, monolátrico, en el Dios único, compasivo y universal que acompaña al siervo sufriente -ique no es otro que el pueblo judío mismo!-, a todos sus exilios y pesares, con la misión de ser luz para las naciones a través del ejemplo legado por sus profetas.

Es en este judaísmo, el de la preponderancia de la Torá oral, puesta luego por escrito en la Mishná y el Talmud, que el mesías es concebido como el rey que redimirá y gobernará a Israel en el clímax de la historia humana. Los rabinos enfocan a través del rey mesías, מלפא משיחא (Malka Meshija) -en arameo-, a los ימות המשיח (Yemot Hamashíaj), los Tiempos Mesiánicos.

Así, del mesías se esperaba las idílicas bendiciones de los profetas: "Porque de Sión vendrá la sabiduría para los pueblos". "Y administrará la justicia entre los gentiles". "Ningún pueblo levantará espada el uno contra el otro". Ideas en Jeremías, Ezequiel, Zacarías y Malaquías. Literalmente, que derrotase a los enemigos de Israel; que regresara al pueblo a su tierra y los reconciliara con Dios introduciendo un período de gozo espiritual y físico. Sería profeta, guerrero, juez, rey y maestro de la Torá.

Con la derrota terrible de la Revolución contra Roma de Bar Kojbá, a quien Rabí Akiba había declarado mesías, la idea nacionalista-naturalista se espiritualizó. 
No obstante, ello demuestra dramáticamente que el mesías es plenamente humano. No desplaza ni a Dios ni a la Torá. Para el judaísmo, el autor final de la redención no es el mesías sino Dios.

Esto ocurría paralelamente a las primeras expansiones de los cristianos. Un paralelismo notable, sin duda, que podría venir a significar que tanto cristianismo como el judaísmo rabínico tienen aproximadamente la misma antigüedad, y comparten además visiones más comunes frente a lo mesiánico de lo que se piensa. Fue la persecución religiosa más tardía la que sacó a Jesús violenta y definitivamente del imaginario del pueblo judío, y provocó un distanciamiento mutuo, tan doloroso y atroz para el pueblo judío, como larguísimo en términos cronológicos.

A medida que los siglos del primer milenio cristiano avanzan, el Midrash, la alegoría rabínica, va volviéndose más elaborado e imaginativo frente al concepto de mesías. Un Midrash dice que el mesías está escondido en Roma, otro que espera en el Cielo, donde sufre por la agonía de su pueblo. Algunos lo muestran como presente en la Creación del Mundo. Para algunos rabíes, el concepto de mesías precedió a la Creación, y en otros Midrashim, el mesías mismo existe desde antes de la Creación.

Los rabinos concuerdan que es de linaje davídico, basados en Oseas 3: 5 y Jeremías 30: 9. Algunos a su vez esperan un David resurrecto y otros un mesías llamado David. Yojanan ben Zakai, el fundador más importante del judaísmo rabínico, anuncia la venida de Ezequías como el mesías.

En el siglo III se habla del mesías como un mesías leproso. Y José el Galileo, en el Talmud, dice que el nombre del mesías es "Shalom". Y eso merece una exégesis:

שלוֹם (Shalom), de la raíz hebrea שלם (Shalem), en verdad significa "íntegro", "entero", "completo", "pleno". Shalom es antónimo de fragmentación. En la muy antigua bendición sacerdotal de Números 6: 24-26, Shalom es el sello final de los siguientes tres versículos:

"Que Dios te bendiga y te proteja"

"Que Dios te ilumine y agracie"

Que su presencia esté contigo y te conceda Shalom"

En su poderosa sobriedad, cada palabra de esta bendición es parte de una secuencia de atributos: bendición, protección, luz, gracia, compañía y plenitud (Shalom). Cada palabra puede ser vista como un arcano en el camino o un estadio a alcanzar, algo que integrar. Coronada por Shalom, la paz espiritual, la triple bendición, bendice para el camino de la búsqueda de integridad.

"Que Dios te bendiga y te cuide" se refiere a nuestra partida por los caminos exteriores e interiores hacia Shalom.

Como en la mitología, una parte de nosotros que no queremos reconocer se distorsiona y queda encerrada en las profundidades de nuestro ser. En vez de confrontarla e incluirla en la conciencia (Shalom), insistimos en proyectarla sobre nuestro prójimo frente a nosotros, sea individual o colectivamente.

Sigue la bendición diciendo: "Que Dios te ilumine", para que puedas alumbrar tu sombra, y hacerte consciente de ella; y "Que Dios te agracie", que tornes tu monstruo en potencial de luz, entrega, incluso sufrimiento pero que le des sentido, 
como Viktor Frankl. Que la fealdad de lo no reconocido y distorsionado sea transformado por la gracia e invitado a la conciencia.

La tercera y última bendición entonces dice: "Que Dios esté contigo y te otorgue Shalom". Consiste en la integración de la propia sombra en sí mismo. La tarea es hacerse pleno, Shalom, y manifestarse en amor cumpliendo con la voluntad de Dios.

\section{c. חבלי המשיח (Jevlei Hamashíaj): “Dolores Premesiánicos” en el pensamiento rabínico}

En los caminos hacia Shalom se encuentran estos pasos de sombra a luz, de fragmentación a integridad. Y en ellos se halla lo que los rabinos llaman "Jevlei Hamashíaj": los "dolores premesiánicos".

En la Mishná, en el tratado de Sutá, se describe en el final un cuadro escatológico realmente dramático de estos caminos de fragmentación en búsqueda de integración. Nos relata un cuadro tremendo de desmoronamiento moral que sufrirá la generación anterior a la llegada del mesías. Cito textualmente: "Nadie creerá en Dios, desaparecerá la verdad y la humanidad prestará oídos sordos a los llamados de conciencia por su inmoralidad. Los jueces y sabios serán presa de corrupción y no habrá censores adecuados, pues ellos mismos estarán inmersos en el lodo del pecado. Todos perderán la vergüenza, los miembros de la casa se convertirán en enemigos y los rostros de aquella generación se asemejarán al del perro. Así como mira un perro la cara de su amo para ver si está satisfecho de él, así mirarán los gobernantes a los gobernados para satisfacer todos sus caprichos". Y el tratado termina con las palabras: "No tendremos en quién apoyarnos sino en nuestro Padre que está en el Cielo, al que imploraremos para que apresure la llegada del mesías".

Es el profeta Elías el que por nunca haber muerto, sino haber ascendido al Cielo, habrá de venir para anunciar la llegada del mesías. El mesías llegará y tocará el cuerno del Shofar, el cuerno de la Redención, y resucitará a los muertos para llevárselos al mundo por venir, en el que aguardaremos el final de los días, el Día del Juicio luego de lo cual, los justos de todas las naciones irán al Edén y los demás irán al frío Sheól. Esto es una composición aproximada de la escatología judía clásica. Ella sin embargo, no se encuentra canonizada ni sistematizada en texto alguno.

\section{d. El concepto clásico: hacia una escatología judía}

El concepto judío clásico de redención mesiánica en el judaísmo rabínico está modelado en la redención de Egipto. La primera redención, la de la esclavitud, es el modelo y el punto de partida del viaje judío en pos del Reino de Dios, cuyo otro polo es la redención mesiánica.

Y ese es el hermoso sentido último de la Pascua Judía, el Pésaj. En las primeras copas de la fiesta, recordamos nuestra redención de Egipto, cuyo relato nos conduce a través de la historia, llena de Dios, hasta la última copa, la del profeta Elías, quien -como dijimos- anunciará la llegada del mesías. Es decir, la Pascua Judía es la fiesta del recuerdo de la redención histórica, terrena, para aludir a la redención espiritual, total, mesiánica. Una reflejada en la otra. Ser judío es caminar entre una redención y otra, cumpliendo con amor los preceptos, 
para que así como Dios cumplió la promesa a Abraham de liberar a su descendencia de la tierra de Egipto, así también cumplirá su promesa de redimirnos a todos cuando llegue el momento. A todos y no al pueblo judío en particular. La Haggadá, el libro que acompaña la cena pascual, dice claramente, en uno de sus pasajes más conmovedores: "Todo ser humano ha de verse a sí mismo como si él mismo hubiese salido de Egipto". Y no dice "todo judío", dice כל בני אדם (Kol Benei Adam") -todo ser humano-. La Mishná también lo asume inequívocamente: פל חסדי עמות העולם יש להם חלק בעולם הבא "Kol Jasidei Umot Haolam, Yesh Lahem Jelek Beolam Habá”): "Todos los Justos entre las naciones tienen un lugar en el mundo venidero".

Nadie está llamado a salvarse por la adopción del judaísmo, que no es misionero, aunque acepta prosélitos con cariño.

Así, cuando llegamos al final de la cena de la Pascua Judía, llegamos simbólicamente al final de nuestra vida terrena: viene la última copa. La embriaguez de la vida nos ha cansado. Es la hora de la verdad, de recibir al heraldo del más allá, a Elías el profeta. El trae la buena noticia: la muerte no es el fin, sino el regreso a la luz plena. Y esa copa que tomamos tiene sabor a esperanza. La redención mesiánica viene, y si no es en nuestra vida, que sea en la vida de nuestros hijos. Y si no puede ser entonces, que sea en vida de nuestros nietos.

Pero nosotros, según la enseñanza jasídica, tenemos siempre en nuestros más humildes actos la posibilidad de hacer venir el mesías más pronto o más tarde, aunque sea un instante más o menos. Como dice el Talmud, si todos los judíos observasen dos sábados plenamente, llegaría el mesías. Y de allí el entusiasmo de lo mesiánico como motor, motivador, impulsor del amor y el éxtasis, la devoción llena y determinante, alegre, cantante, danzante, agradecida y apegada a Dios, sin desesperar jamás, en estado de "contentamiento" שימחה (Simjá) interior permanente.

No viajamos solos por la mesa de la pascua de la vida. En ella viajamos todos. Y el pueblo judío -entre todos- viaja en misión, entre la redención primigenia y la redención plena. Y el logro en la vida se mide en cuanto de bondad pudimos redimir de en medio del egoísmo, cuanto de amor pudimos redimir de en medio del embotamiento; cuanto de vida pudimos redimir en medio de la muerte. Elías nos pasa a buscar y al hacerlo decimos la última bendición de la cena con las palabras ("Bashaná Habá Beyirushalaim”): "El Próximo Año en Jerusalén”. Si la mundana o la celestial, eso está en el juego del libre albedrío, en el que Dios siempre nos invita a apostar por el amor.

\section{e. En la Edad Media}

En la Edad Media el judaísmo no hereda una escatología sistemática o coherente, sino fragmentos de todo tipo.

Esto da origen a textos muy interesantes, eclécticos muy probablemente, como El libro de Zerubbabel. En él se relatan visiones de Zerubabbel, el último regente de de Judea de la Casa de David. La aparición del mesías viene precedida por la aparición de un rey satánico de Roma, Armilus (que no es otro que Rómulo), un emperador satánico del mundo. Todos creerán en él menos los judíos, quienes combatirán a este monstruo a través del mesías hijo de José -no de David- y por medio 
de una mujer llamada Hefzibah. Este premesías traerá a todos los judíos de vuelta a la tierra de Israel, pero Armilus lo vencerá y matará. Jerusalén es salvada por esta misteriosa mujer, Hefzibah, y entonces se alzará el mesías hijo de David, y comenzará la Era Mesiánica.

Maimónides ve al mesías como redentor nacional, no místico. Y el rabí Abraham bar Hiyya, un filósofo racionalista, trató de establecer por cálculos astrológicos la fecha de la venida del mesías. Todo ese orbe existía en el seno del pueblo judío ante la esperanza mesiánica, durante la Edad Media.

El Renacimiento y El Barroco, tanto en Europa como en los territorios musulmanes, encuentra al pueblo judío acosado continuamente por la persecución y la matanza, y a continuación una serie de mesías surgen, cuya noticia se esparce como reguero de pólvora por una diáspora desesperada. Desde Shabbtai Tzví, hasta Frank, pasando por numerosos otros "mesías" -al revelarse incapaces de anunciar una redención-, van sumiendo al pueblo en una depresión: una depresión que solo curó la esperanza emancipadora en Europa Occidental, la Revolución Jasídica en Europa Oriental, y el Sionismo, ya entrado el siglo XIX.

\section{f. La Epoca Moderna}

La Epoca Moderna trajo a Europa Central y Occidental la Reforma Judía. Ella sustituyó la creencia en un mesías individuo por una creencia en una Era Mesiánica, que a fines del siglo XVIII y en el XIX se enamoró del progreso, la ciencia y la emancipación aparente, a ratos declarando que esa Era estaba a la vuelta de la esquina.

\section{EPÍLOGO}

La Shoah, el genocidio de seis millones de judíos, destruyó ese sueño rosado, y lo hizo cenizas y silencio ante el sufrimiento indecible y la ausencia de Dios. El Sionismo como movimiento de liberación nacional judío se apartó de todo mesianismo religioso, y pretendió dar hogar al pueblo diezmado y perseguido, con los brazos arremangados, pala y -contra su voluntad-fusil.

En 1956, en "Preguntas que judíos se hacen”, el rabino Mordejai Kaplan, fundador del Movimiento Reconstruccionista, escribe: "Ya no podemos creer en que alguna persona o ser semidivino está divinamente destinado a regir como el mesías y auspiciar el milenio. No obstante, la idea de mesías puede aún figurar simbólicamente para expresar la valiosa creencia en un tipo más refinado de humanidad que este mundo aún no ha conocido".

En la ortodoxia judía, especialmente en el jasidismo ortodoxo, la espera mesiánica es muy carismática, activa y central. Cada judío, pasito a pasito, precepto a precepto, amor a amor, va adelantando la venida del mesías, que se espera con impresionante fervor cada final de Shabbat, cada final de Pascua y otros momentos del calendario, en una devoción indemne por la historia, y acaso, motivada por ella misma.

El mesías es motor y motivador, es escape y es transmutación de dolor, es anticipado por el trabajo humano, y otorgado ante el mérito humano, por Dios. Es necesario y vital, al tiempo que mítico e ilusorio. 
Ante esta idea, el Dr. Viktor Frankl, psiquiatra judío, sobreviviente de Auschwitz, plantea su sublime y sobria logoterapia. Quien concibe su sentido, ante el sufrimiento más extremo, y ama desde ese sentido que se construye y refina, aggiorna día a día, ese ser humano, y ese pueblo, no solamente sobrevive, sino que vive y trasciende ante la Presencia de Dios.

\title{
RESUMEN
}

El artículo se pregunta por la motivación para pensar en torno a cambios epocales o de era y sus expresiones religiosas; reflexiona sobre los temores y esperanzas de un milenarismo (entendido como umbral), y sobre la psicología profunda ante el fenómeno, por un lado, y la manifestación externa de ese cambio de era, por otro. Subraya la sensación de adviento, de advenimiento de algo, un sentido de umbral que augura un gran cambio. Luego analiza el milenarismo y el mesianismo desde una perspectiva judía, presentando una panorámica que cubre desde los tiempos del rey David hasta nuestros días intentando develar el sentido y las transformaciones del concepto mesiánico judío. Para ello presenta la prehistoria del mesianismo en la Biblia hebrea y estudia la aproximación al tema en el pensamiento rabínico antiguo, medieval y moderno. Para el judaísmo rabínico la primera redención, la de la esclavitud, es el modelo y punto de partida del viaje judío en pos del Reino de Dios, cuyo otro polo es la redención mesiánica. Y aquí reside el sentido último de la Pascua Judía, el Pésaj, considerada como la fiesta del recuerdo de la redención histórica, terrena, para aludir a la redención espiritual, total, mesiánica. Ser judío es caminar entre una redención y otra, asumiendo que 'todos los justos entre las naciones tienen un lugar en el mundo venidero'.

\begin{abstract}
The article considers the motivations which led people to think of a change of era and their religious experiences. The author considers the fears and hopes of a milleniarism (regarded as the summit), one's deepest psychology when faced with this phenomenon and the external manifestations of these changes. The author highlights the feeling of advent, the coming of something, which will bring about great changes. The article then analyses the milleniarism and messiahnism form a Jewish perspective, presenting a panoramic view from the times of King David until today, in an attempt to disclose the sense and transformations of the Jewish messianic concept. The article presents the prehistory of messiahnism in the Hebrew Bible and looks into the way this topic has been dealt with in the old, medieval and modern Rabbinical thought. For Rabbinical Judaism, the first liberation, from slavery, is the model and starting point of the Jewish journey towards the Kingdom of God. Here lies the deepest weaning of the Jewish Passover, the Pésaj, regarded as the historical and earthly memorial which evokes the fullness of the spiritual messianic redemption. Being a Jew entails wandering between these two redemptions, assuming -as Talmudic teaching States- that 'all the just among the nations have got a place in the coming world'.
\end{abstract}

